\title{
Distortionary, Non-Distortionary, and Distributional Properties of Environmental Taxes: Extension of Sandmo's Observation*
}

\author{
Talbot Page \\ Dept. of Economics, Brown University, Providence, RI02912, USA \\ E-mail: Talbot_Page@Brown.edu \\ and \\ Qinghua Zhang \\ Dept. of Applied Economics, Guanghua School of Management \\ Peking University, Beijing 100871, China \\ E-mail: zhangq@gsm.pku.edu.cn
}

\begin{abstract}
We find a limited parallel between lump-sum taxes and environmental taxes. Corollary 2, which extends Sandmo's observation, shows that appropriated corrective revenues have the same non-distortionary effects as lump-sum taxes, the result reducing to the original observation when the appropriated corrective revenues meet the revenue need and achieve first-best efficiency with other taxes set at zero.

Corollary 1 finds that when the corrective part of environmental taxes is used as marginal damage compensation, the non-corrective part is distortionary and symmetric with ordinary proportional labor taxes in second-best equilibria.

The extension of Sandmo's observation suggests that environmental taxes may be among the least distortionary taxes in the tax system. (c) 2006 Peking University Press
\end{abstract}

Key Words: Environmental taxes; Pigovian taxes; Lindahl prices; Second-best taxes; Distortionary taxes; Lump-sum taxes.

JEL Classification Numbers: D58, D62, H23, L51, Q2, Q48.

* We wish to thank Roberton Williams, Lawrence Goulder, Kerry Smith, Don Fullerton, Dan Usher, John Hartwick, Jim Hines, John Skinner, Pravin Krishna, Klaas Vant Veld, Rich Howarth, Jim Feyrer, Herakles Polemarchakis and Harl Ryder for helpful comments. Remaining mistakes are our own.

157 


\section{INTRODUCTION}

Almost 30 years ago Sandmo (1975, p.94) observed that environmental taxes achieved first-best efficiency (and thus are non-distortionary) when they are set at their corrective Pigovian levels, if their revenues meet the government's revenue need and other taxes are set at zero. Similarly, lumpsum taxes achieved first-best efficiency (and thus are non-distortionary) when they are large enough to meet the revenue need with other taxes set at zero. Moreover, it seems plausible that when revenues from corrective taxes are less than but close to the revenue need, the tax system might come close to first-best efficiency, in a similar way to when lump-sum taxes are less than but close to meeting the revenue need the

With these observations in mind, we ask the question: To what extent is there a parallel between environmental taxes and lump-sum taxes? A parallel of course would be limited. Environmental taxes (more precisely externality taxes ${ }^{1}$ ) are designed to change the behavior of producers of environmental harms while lump-sum taxes do not have marginal incentive effects, except from wealth effects.

We find a limited parallel. A defining difference between environmental and other taxes is that the former have a corrective Pigovian part, while the latter do not. But environmental taxes may also have a non-corrective part when they are set higher or lower than at their corrective levels. Theorem 1 and Corollary 1 show that the non-corrective part of environmental taxes is distortionary, behaving symmetrically with a proportional labor tax when the corrective revenues are used as marginal damage compensation to recipients of environmental harms. In this case we find the whole environmental tax is typically higher than its first-best Pigovian level.

But in a parallel, Theorem 3 identifies an equivalence relation between corrective Pigovian revenues of environmental taxes and lump-sum taxes. Corollary 3 confirms the intuition that when appropriated Pigovian revenues come close to meeting the revenue need, the second-best tax system comes close to first-best efficiency. Corollary 2 extends Sandmo's observation by showing that, whether or not there are other taxes, appropriated corrective revenues are non-distortionary sources of general revenue in the same way that lump-sum taxes are non-distortionary sources; and when appropriated corrective revenues equal the revenue need, the second-best tax-system is first-best. The above results apply to ordinary proportional taxes are zero and the corrective parts of ordinary taxes generate no revenues.

\footnotetext{
${ }^{1}$ It has become a common usage to analyze externality taxes under the heading of environmental taxes, and we follow that usage here, except sometimes when the defining properties of externalities are being highlighted.
} 
Other papers have found non-distortionary properties of environmental taxes. Kaplow (1996) showed that in the presence of distortionary taxes, taxes based on marginal benefits can in principle finance public goods without additional distortionary costs, and he applied this idea to environmental taxes, which produce the public goods of environmental quality. Fullerton and Metcalf (2001) found that environmental taxes and other forms of regulation can create rents, which when taxed away lower the distortionary cost of the taxed system, compared with forms of regulation that leave the rents with the producers. Both papers are related to ours, but neither addresses the extension of Sandmo's observation or the parallel with lump-sum taxes.

Our results are consistent with Bovenberg and de Mooij (1994), Oates (1994), Fullerton (1997), and Bovenberg and Goulder (2002) in their conclusions that in a second-best equilibrium marginal benefits of environmental taxes are offset by marginal costs elsewhere. But the extension of Sandmo's observation appears to be contrary to the conclusion by Bovenberg and de Mooij (p. 916, 1997) that environmental taxes "tend to be more, rather than less, distortionary than other taxes."

The potential revenue from corrective Pigovian taxes is large, perhaps in the hundreds of billions annually ${ }^{2}$, and thus it appears that environmental taxes (and auctioned marketable allowances) could be among the least

\footnotetext{
${ }^{2}$ Consider just a few examples from the environmental damage assessment literature. The EPA's central estimate for the benefits of the Clean Air Act for the year 2000 is $\$ 71$ billion (Environmental Protection Agency, p. iii, 1999). Shrank and Lomax (2001) estimated $\$ 78$ billion annual costs from wasted time and gasoline due to highway congestion (the estimate excludes costs of increased air pollution, costs of increased maintenance and capacity; the $\$ 78$ billion estimate is for 68 urbanized areas which include about $75 \%$ of the urbanized areas in the US). Porter (1999) estimated an annual external cost from automobile air pollution of $\$ 27$ billion, $\$ 60$ billion from non-driver fatalities(p.194), and cites the $\$ 90$ billion annual cost of road administration, maintenance and capital outlay, much of which is externally borne cost, including the wear and tear from trucks from their heavy axle loadings (p. 161). Porter cites 9 other studies with estimates of external costs driving in the range of $\$ 500$ billion to $\$ 1$ trillion annually (p. 194). Newman and Kenworthy (1999, p. 56) list 5 studies for the US and 3 for other countries (with some overlap with Porter's citations). These estimates range from about $\$ 400$ to 800 billion in annual external costs for the US. Vickrey estimated the congestion cost of cars in Manhattan to be about $\$ 15$ per car per trip into the island (personal communication). H. Uzawa (1974, p. 98) estimated the external cost of driving to be in the range of $\$ 3000$ to $\$ 4000$ in current dollar values per car per year, comparable to other estimates. The IPCC offers a range of estimates of a carbon tax to internalize environmental costs of climate change. The estimates range form $\$ 10$ to $\$ 100$ per ton, which translates for an annual 6 billion tons emissions worldwide with roughly 1.25 billion tons of US emissions to a possibly appropriable Pigovian revenue in a range of $\$ 12.5$ to $\$ 125$ billion for the US. Most of these estimates are based on average damages. Converting to marginal damages, appropriate for an estimate of the Pigovian revenue, would tend to increase estimates of Pigovian revenues. In the other direction, only a portion of Pigovian revenues are collectable and available as a tax revenue source.
} 
distortionary sources of revenue in the tax system. At the same time, the parallel with lump-sum taxes suggests that greater attention be paid to distributional effects of environmental harms even in the case of nonregulation, where Theorem 3 also applies.

The paper is organized as follows. Section 2 summarizes first-order conditions for a simple case without externalities. Section 3 extends these observations to include externalities and derives the main results. Section 4 discusses tax interaction effects. Section 5 is on policy.

\section{THE BASELINE CASE OF PROPORTIONAL TAXES WITHOUT ENVIRONMENTAL HARMS}

Consider the model (1)-(6) below, without externalities, where each individual $i$ consumes $x_{i}$ of the private good, $z$ of the public good and supplies $L_{i}$ units of labor. The private good $x$ is produced with labor and capital and the public good $z$ is produced with labor alone. Each $i$ is endowed with $\bar{K}$ units of capital (corn), which can either be consumed directly or supplied as a factor in producing $x$. We will find a symmetry between this simple model and a model with externalities.

$$
U^{i}\left(x_{i}, z, L_{i}, \bar{K}-K_{i}\right)
$$

Quasi-concave utility for individual $i$, increasing in $x_{i}$ and $z$ and decreasing in $L_{i}$ and $K_{i}$.

$$
x=f\left(L_{x}, K_{x}\right)
$$

Production function for the private $\operatorname{good} x$.

$$
z=h\left(L_{z}\right)
$$

Production function for the private $\operatorname{good} z$.

Where we assume constant returns to scale (CRS) in production and a representative agent form of utilities with $U^{i}(\cdot)=U(\cdot)$. Besides the market clearing equations, the Walrasian equilibrium conditions come from:

$$
\begin{gathered}
\max _{x_{i}, L_{i}, K_{i}} U\left(x_{i}, z, L_{i}, \bar{K}-K_{i}\right) \text { subject to } P_{x} x_{i}=w L_{i}+r K_{i}-M_{i}(\operatorname{each} i) \\
\max _{L_{x}, K_{x}} P_{x} f\left(L_{x}, K_{x}\right)-(w+v) L_{x}-(r+\gamma) K_{x} \\
w L_{z}=\gamma K+v L_{x}+M
\end{gathered}
$$

where in the consumers' maximization problem (4), $P_{x}$ is the prices of $x$, labor is the numeraire good with wage $w=1, r$ is the rental rate of 
capital, and $M_{i}$ is the lump-sum tax on $i$ (a fixed tax possibly constrained to zero). In the $x$-industry's problem (5), $v$ and $\gamma$ are proportional taxes on labor and capital respectively. In the government's budget constraint (6), expenditures $w L_{z}$ on $z$ equal revenue sources from capital, labor and total lump-sum taxes $M=\sum M_{i}$. Labor producing the public good is untaxed ${ }^{3}$.

Define $i$ 's marginal benefits from the public good by $\hat{p}_{i}=\frac{-U_{z}^{i}}{U_{L}^{i}}$ (where $U_{z}^{i}=\frac{\partial U^{i}}{\partial z}$ and $U_{L}^{i}=\frac{\partial U^{i}}{\partial L_{i}}$ ), the sum of as (where is the aggregate Lindahl price), and the net social benefit as $\sum_{i} U^{i}$. To reduce Kuhn-Tucker analysis we consider only internal equilibria where the non-negativity constraints $L_{i}, K_{i}, x, z \geq 0$ are not binding.

Observation 1 says that in Walrasian equilibrium, with incremental changes in taxes, the change in the normalized equals the change in the net benefit of the public good minus the change in the distortionary costs of the taxes.

OBSERVATION 1. First-order conditions for a Walrasian equilibrium for taxes $\gamma, v$, and $M$ are

$$
\begin{aligned}
\frac{d(N S B)}{-U_{L}} & =\overbrace{\left(\hat{p} h_{L}-1\right) d L_{z}}^{\text {marginal net benefit }}+\overbrace{\gamma d K_{x}+v d L_{x}}^{\text {marginal distor'y costs }} \\
\underbrace{d L_{z}}_{\text {expenditure }} & =\underbrace{\left.d\left(\gamma K_{x}\right)+d(v L) x\right)+d M}_{\text {revenue sources }} .
\end{aligned}
$$

Proof. Condition (8) follows from taking the differential of the budget constraint (6) and recalling that $w=1$. See the Appendix for (7). In (7), $\hat{p} h_{L}$, where $h_{L}=\frac{\partial h}{\partial L_{z}}$, is the value of the marginal product of a unit labor in producing $z$, valued in units of labor, and 1 is the marginal resource cost of labor in units of labor, so $\left(\hat{p} h_{L}-1\right)$ is the marginal net benefit of the public good financed by taxes. The term $\gamma d K_{x}$ and $v d L_{x}$ are differential distortionary benefits or the negative of the marginal distortionary costs of taxes $\gamma$ and $v$.

In a second-best equilibrium, change in $\gamma$ and $v$, with fixed $M$, must not increase the net social benefit, and setting $d(N S B)=0$, we get from Observation 1:

\footnotetext{
${ }^{3}$ As a background assumption, for the Walrasian equilibrium to be an appropriate solution concept, we assume $x_{i}$ is a small fraction of $x$, and there are small many small firms.
} 
OBSERVATION 2. First-order conditions for a second-best $\gamma$ and $v$, with fixed $M$, are

$\frac{d(N S B)}{-U_{L}}=\left(\hat{p} h_{L}-1\right) d L_{z}+\gamma d K_{x}+v d L_{x}=0$ and $d L_{z}=d\left(\gamma K_{x}\right)+d\left(v L_{x}\right)$,

where the condition on the right side is (8) with $d M=0$.

The idea of Observation 2 is that in a second-best equilibrium, the marginal net benefit of the public good, $\left(\hat{p} h_{L}-1\right) d L_{z}$, equals the sum of the marginal distortionary costs of the taxes used to finance it. Alternatively, the observation can be interpreted to say that in a second-best equilibrium the marginal cost of raising an extra $\$ 1$ in public funds must equal the marginal benefit of the public good financed by this dollar. ${ }^{4}$

Observation 1 and 2 satisfy a permutation symmetry. Exchanging $v$ and $\gamma$ and exchanging $L_{x}$ and $K_{x}$ leave the form of the first-order conditions the same in the two observations. The symmetry in first-order conditions is not surprising, given the symmetry of the model itself. The taxes $\gamma$ and $v$ are Ramsey taxes and typically positive, although one can be negative (but not both) when there are sufficiently strong complementarities built into the production and/or utility functions.

Next consider the first-order conditions for the lump-sum tax $M$. Write $\lambda_{1}$ for the shadow price of the upperbound constraint $\bar{M}$ and $V_{\bar{M}}(\bar{M})$ for the value function associated with the envelope theorem.

ObSERvation 3. First-order conditions for second-best $M$ are

$$
\begin{gathered}
\text { either }\left(M \leq \bar{M} \text { and } \lambda_{1}=0\right) \text { or }\left(M=\bar{M} \text { and } \lambda_{1}>0\right) \\
V_{\bar{M}}(\bar{M})=\lambda_{1}
\end{gathered}
$$

Proof. See Appendix.

Condition (10) is the slack complementarity condition for the upperbound constraint $\bar{M}$ and (11) says that the value function is the shadow price of $\bar{M}$. When $\lambda_{1}>0$ and the upperbound constraint $\bar{M}$ is strictly

\footnotetext{
${ }^{4}$ To see this, rearrange (9) to $\hat{p} h_{L}=1-\left(\gamma d K_{x}+v d L_{x}\right)$, where incremental changes in the taxes are chosen to satisfy the budget constraint with $d L_{z}=1$. Recalling that $w=1$, the incremental increase in public funds is $\$ 1$. The marginal benefit of the increase $d L_{z}=1$ is $\hat{p} h_{L}$. The marginal cost of the extra $\$ 1$ is the increase in distortionary cost $-\left(\gamma d K_{x}+v d L_{x}\right)$ plus the 1 unit of labor drawn from the private sector to produce the public good.
} 
binding, we will say there is a revenue need (and we also identify $\lambda_{1}=0$ as a necessary condition of first-best efficiency). It follows from (10) that when there is a revenue need and the upperbound constraint $\bar{M}$ is relaxed, the second-best $M$ increase, and by condition (11) NSB increases.

With the constraint of revenue neutrality, the government's budget is held at constant $\bar{G}$. Then $d \bar{G}=d L_{z}=0$ and (7) becomes $\frac{d(N S B)}{-U_{L}}=$ $\gamma d K_{x}+v d L_{x}$. In other, words, in a Walrasian equilibrium with revenue neutrality, when distortionary costs decrease incrementally, the normalized $N S B$ increases by the same amount. And when $d L_{z}=0$ from revenue neutrality, $\gamma d K_{x}+v d L_{x}=0$ from (9). Thus in a second-best equilibrium, if we make incremental changes in taxes $\gamma$ and $v$ in a way that preserves revenue neutrality, then the sum of the distortionary tax interaction effects must add to zero. This means, for example, that in a second-best equilibrium with revenue neutrality, if an incremental change in $\gamma$ decreases its ownprice distortionary cost, then the change "exacerbates" the distortionary costs of the sum of the other three own-price and cross-price distortionary tax interaction effects.

Next we modify and extend (1) - (6) to take into account externalities.

\section{DISTORTIONARY AND NON-DISTORTIONARY PROPERIES OF ENVIRONMENTAL TAXES}

There are two main differences between negative externalities and ordinary private goods: negative externalities impose involuntarily borne costs and these costs may be borne by many people simultaneously. Taking these differences into account leads to model (1') - (6') as follows. In (1') replace the private good $K_{i}$ by the public bad (externality) "smoke" $S$, where $S$ has no subscript (because it is a public bad affecting everyone simultaneously) and $S$ is not a decision variable for individual $i$ (because it is involuntarily borne).

$$
U^{i}\left(x_{i}, z, L_{i}, S\right)
$$

Quasi-concave utility for individual $i$, increasing in $x_{i}$ and $z$ and decreasing in $L_{i}$ and $S$.

$$
x=f\left(L_{x}, S\right)
$$

Production private good $x$, with CRS.

$$
z=h\left(L_{z}\right)
$$

Production public good $z$, with CRS.

Instead of modeling abatement as separable end-of-pipe treatment, which can overstate the costs of treatment, in (2') we subsume abatement opportunities in the production function $f$. "Smoke" is a factor of production in 
the sense that when polluters pay a price for each unit of emission, they have an incentive to optimize on the use of smoke in the same way they have an incentive to optimize on labor when they pay a price for each unit of labor. The model applies to externalities from congestion and depletion, as well as pollution. ${ }^{5}$

Corresponding to the capital tax of the baseline model is a (per unit) environmental tax $t$ collected from the smoke emitting $x$-industry. Corresponding to $i$ 's marginal benefit from the public good, $\hat{p}=\frac{-U_{z}^{i}}{U_{L}^{i}}$ and sum of the marginal benefits $\hat{p}=\sum_{i} \hat{p}_{i}$, define the marginal damage of smoke to $i$ as $\hat{t}_{i}=\frac{U_{S}^{i}}{U_{L}^{i}}$, and sum of the marginal damages $\sum_{i} \hat{t}_{i}=\hat{t}$.

Divide the environmental tax $t$ into two parts, $t=\hat{t}+\tau$, where $\tau$ is a surtax, which is positive or negative depending on whether the environmental tax $t$ is greater or less than its corrective Pigovian level $\hat{t}$. Define the Pigovian revenues as $\hat{t} S$ and divide it into two parts. One part, the Pigovian compensation, is earmarked to compensate the recipients of the environmental harm. We call the remaining part the appropriated Pigovian revenue. The two decompositions will reveal symmetries between model (1) - (6) and model (1') - (6'), between the surtax and the labor tax, and between the appropriated Pigovian revenue and lump-sum taxes.

The appropriated revenue is used to finance the public good or reduce taxes. Define the individual appropriated Pigovian revenue to be $\alpha_{i} S$, where $\alpha_{i}$ is a constant rate of appropriation chosen by the government, and define the aggregate appropriated Pigovian revenue to be $\alpha S$, where $\sum \alpha_{i}=\alpha$. Define the individual compensation to each $i$ to be $\left(\hat{t}_{i}-\alpha_{i}\right) S$, and the aggregate Pigovian compensation to be $(\hat{t}-\alpha) S$. By construction, the aggregate appropriated Pigovian revenue $\alpha S$ and aggregate Pigovian compensation $(\hat{t}-\alpha) S$ add to the aggregate Pigovian revenue $\hat{t} S$. There can be upperbound constraints $\alpha_{i} \leq \bar{\alpha}_{i}$ (all $i$ ) and an aggregate upperbound constraint $\alpha \leq \bar{\alpha}$. When $\alpha=\hat{t}$, we say that the Pigovian revenue is fully appropriated.

When compensation is paid, there is the possibility that individuals will not undertake their efficient defensive or avoidance strategies. For example, when individuals are compensated for airport noise they may live inefficiently close to the airport-the "coming to nuisance" problem of concern to Coase (1960). On the other hand, when compensation is not conditioned on the individuals' actual actions but on the estimated harms under efficient defensive strategies, individuals have an incentive to take their ef-

\footnotetext{
${ }^{5}$ For example, in the problem of highway congestion where each commuter faces a congestion tax, each commuter has a production function that produces trips with factors of her time, her car's gasoline, oil and capital depreciation, and congestion costs imposed on others, internalized through a congestion tax.
} 
ficient defensive strategies. ${ }^{6}$ Alternatively, some environmental harms are pervasive, and individuals have little opportunity for defensive strategies. For example, people still carry traces of the long-banned DDT, and there is little they can do about this widespread pesticide. In the policy discussion, we will focus on the case of little or no compensation, in which case the issue of "coming to the nuisance" has little importance. With this in mind, we will use for now the simplifying assumption that environmental harms are pervasive, with no defensive strategies available. ${ }^{7}$

The surtax revenue $\tau S$ is always appropriated by the government to finance the public good or reduce other taxes. When $\tau$ is negative, the negative surtax revenue is financed by the appropriated Pigovian revenue or by other tax revenues.

We assume two forms of utility. The first, a representative agent form, where $U^{i}\left(x_{i}, z, L_{i}, S\right)=U\left(x_{i}, z, L_{i}, S\right)$, is useful to analyze distortionary effects but limited uin analyzing distributional effects. The second, an additively separable form similar to the one used to study Groves taxes in the mechanism design literature, includes more distributional effects. In this second form, define $i$ 's utility, with a slight abuse of notation, as $U^{i}\left(x_{i}, z, S\right)-L_{i}$ (see Green and Laffont, pp. 29-32, 1980). ${ }^{8}$

We consider only internal equilibria with non-negativity constraints $L_{i}, x$, $z, S \geq 0$ non-binding, and environmental taxes as the only instruments of environmental regulation. ${ }^{9}$ Besides the market clearing equations, the Walrasian equilibrium conditions come from:

$$
\max _{x_{i}, L_{i}} U\left(x_{i}, z, L_{i}, S\right) \text { subject to } P_{x} x_{i}=w L_{i}+\left(\hat{t}_{i}-\alpha_{i}\right) S-M_{i}(\operatorname{each} i)
$$

\footnotetext{
${ }^{6}$ A similar idea is used in tort law under "comparative negligence" where compensation is paid not to the amount of actual total damages but on the proportion of the damages attributable to the defendant. By not being compensated for the amount the plaintiff contributed to the harm by his actions, the plaintiff is given incentives to undertake efficient defensive or avoidance strategies.

${ }^{7}$ As a background assumption, we assume that in his judgment individual $i$ 's actions negligibly affect the aggregate $S$ and his $\hat{t}_{i}$ (with pervasive $S$ ). These assumptions parallel the assumption that $i$ 's actions negligibly affect the price $P_{x}$.

${ }^{8}$ Espinosa and Smith (2002) found that computable general equilibrium estimates of second-best taxes can vary sensitively with separability specifications. The theorems and corollaries below are sufficiently general to hold for both specifications of utility, one with no separability assumptions and the other with a strong assumption of separability.

${ }^{9}$ With modification, the theorems and corollaries carry over to situations where there are other regulatory controls. For example, auctioned marketable permits are similar to environmental taxes with $\alpha_{i}=\hat{t}_{i}$; "grand-fathered" marketable permits are similar to environmental taxes with the environmental revenue returned to the producers; optimized command-and-control is similar to grand-fathered marketable permits with no gains from permit trading. The parallel between environmental taxes and auctioned marketable allowances abstracts from differences in uncertainty.
} 


$$
\begin{gathered}
\max _{L_{x}, S} P_{x} f\left(L_{x}, S\right)-(w+v) L_{x}-(\hat{t}+\tau) S \\
w L_{z}=\alpha S+\tau S+v L_{x}+M
\end{gathered}
$$

where in $\left(4^{\prime}\right),\left(\hat{t}_{i}-\alpha_{i}\right)$ is individual $i$ 's rate of compensation, and $S$ is not a decision variable for $i$. In $\left(6^{\prime}\right)$, expenditures $w L_{z}$ on $z$ equal the revenue sources of the appropriated Pigovian revenue, the surtax revenue, revenue from the tax on labor in the $x$-industry and the lump-sum revenue $M$ where $\sum M_{i}=M$. The following examples illustrate model $\left(1^{\prime}\right)-\left(6^{\prime}\right)$.

EXAMPLE 3.1. $\quad\left(\hat{t}_{i}=\alpha_{i}, M_{i}=0\right.$ all $i$, and $\tau$ and $v$ unconstrained $)$.

This is a simplified case of the recent literature. ${ }^{10}$ With $\alpha_{i}=\hat{t}$ the Pigovian revenue is fully appropriated by the government, and this revenue added to the surtax revenue is $\alpha S+\tau S=\hat{t} S+\tau S=t S$, so the entire environmental tax is appropriated by the government as general revenue. The environmental tax is unconstrained because $\tau$ is unconstrained.

EXAmPLE 3.2. $\quad\left(\alpha_{i}=M_{i}=0\right.$ all $i, \tau=0$ and $v$ unconstrained $)$.

This is an early case in the environmental economics literature. In this case, the environmental tax $t$ equals its corrective Pigovian level $t=\hat{t}$ and the Pigovian revenue is returned on a marginal damage basis as compensation to the harm recipients.

The corrective Pigovian taxes of this case are similar to Lindahl prices (or taxes), except that Pigovian taxes are applied to public bads, Lindahl taxes to public goods. Individual Lindahl taxes, set at $\hat{p}_{i}$, are marginal benefit taxes and the aggregate tax $\hat{p}$ finances the public good, while the individual Pigovian $\hat{t}_{i}$ are marginal damage compensation rates and the aggregate environmental tax $t=\hat{t}$ controls the public bad. Together, they achieves first-best efficiency.

Both individual Lindahl marginal benefit taxes $\hat{p}_{i}$ and individual Pigovian marginal damage compensation rates $\hat{t}_{i}$ are useful analytic tools. Both are impractical. Both are set aside when it comes to practical policy application. Yet, providing the efficient amount of the public good requires estimating the aggregate $\hat{p}$, and controlling public bads to efficient levels requires estimating the aggregate $\hat{t}$. Fortunately, both $\hat{p}$ and $\hat{t}$ can be estimated with less relative error than estimating the individual $\hat{p}_{i}$ and $\hat{t}_{i}$.

\footnotetext{
${ }^{10}$ The simplified case lacks a second "clean" good but doesn't require revenue neutrality. See Page and Zhang (2000) for an added second private good, extending (1')—(6') to include models by Goulder et al. (1999), Bovenberg and de Mooij (1994) and Parry (1995), but needing additional adjustments to deal with linearity assumptions in the latter two models.
} 
ExAmPle 3.3. $\quad\left(\alpha=M_{i}=0\right.$ all $i, \tau=-\hat{t}$ and $v$ unconstrained $)$.

This case models non-regulation. The environmental tax facing the polluters is $t=\hat{t}+\tau=\hat{t}-\hat{t}=0$, so the polluters are unregulated. The fully appropriated Pigovian revenue $\hat{t} S$ is completely used up financing the negative surtax revenue $(-\hat{t} S)$ so that there is no net environmental revenue obtained by the government. And with $\alpha_{i}=\hat{t}_{i}$ (all $i$ ) no one is compensated for environmental harms.

Theorem 1 corresponds to Observation 2 and identifies $\tau$ as a distortionary tax.

THEOREM 1. First-order conditions for second-best labor and environmental taxes, for fixed $\alpha$ and $M$, (and $\alpha_{i}=\alpha_{j}, M_{i}=M_{j}$, all $i$ and $j$, with representative agent utility), are

$$
\begin{aligned}
\frac{d(N S B)}{-U_{L}} & =\left(\hat{p} h_{L}-1\right) d L_{z}+\tau d S+v d L_{x}=0 \\
d L_{z} & =d(\alpha S)+d(\tau S)+d\left(v L_{x}\right) .
\end{aligned}
$$

Proof. See Appendix for (12); (13)is the differential of (6') with fixed $M$.

The proof in the Appendix closely follows the proof of Observation 2, with differences underlined. The restrictions of $\alpha_{i}=\alpha_{j}, M_{i}=M_{j}$, which preserve a world of equals, are needed for the proof with the representative agent utilities but not for additively separable utility. When $\alpha=0$, the first-order conditions of Theorem 1 satisfy permutation symmetry, as in Observation 1 and 2. Exchanging $v$ for $\tau$, and exchanging $L_{x}$ for $S$, leaves the form of the first-order conditions the same. When $\alpha \neq 0$ the symmetry still goes through in (12), but is broken in (13). Summarizing,

COROLlary 1. In a second-best equilibrium there is a permutation symmetry between the environmental surtax and the labor tax if and only if $\alpha=0$.

In the usual case when $\alpha_{i} \geq 0$ (all $i$ ), $\alpha=0$ implies $\alpha_{i}=0$ (all $i$ ), in which case there is full Pigovian marginal damage compensation. The labor tax $v$ is a Ramsey tax, and when $\alpha=0$ the environmental $\operatorname{surtax} \tau$, with its permutation symmetry, behaves like a Ramsey tax too. Behaving like a Ramsey tax when $\alpha=0$, second-best $\tau$ is typically positive but can 
be negative because of complementarities. ${ }^{11}$ When $\alpha \neq 0$, condition (12) remains the same and $\tau$ is still distortionary tax but no longer exchanges roles with $v$, because of the extra source of the appropriated Pigovian revenue $d(\alpha S)$ in (13). When $\alpha=\hat{t}>0$, the main case of the recent literature, it has been found that second-best $\tau$ is often negative.

Theorem 2 extends Observation 3 to include externalities and reveals a parallel between the appropriated Pigovian revenue and lump-sum taxes. Write $\lambda_{1}$ and $\lambda_{2}$ for the shadow prices for $\bar{M}$ and $\bar{\alpha}$ respectively, and $V_{\bar{M}}(\bar{M})$ and $V_{\bar{\alpha}}(\bar{\alpha})$ for the value functions.

Theorem 2. (Appropriation of the Pigovian Revenue). First-order conditions for second-best $M$ and $\alpha$ are

$$
\begin{aligned}
& \text { either }\left(M \leq \bar{M} \text { and } \lambda_{1}=0\right) \text { or }\left(M=\bar{M} \text { and } \lambda_{1}>0\right) \\
& \text { either }\left(\alpha \leq \bar{\alpha} \text { and } \lambda_{2}=0\right) \text { or }\left(\alpha=\bar{\alpha} \text { and } \lambda_{2}>0\right) \\
& S \lambda_{1}=\lambda_{2} \\
& V_{\bar{M}}(\bar{M})=\lambda_{1} \text { and } V_{\bar{\alpha}}(\bar{\alpha})=\lambda_{2}
\end{aligned}
$$

Proof. See Appendix.

Conditions (14) and (15) are slack complementarity conditions for the upperbound constraints $M \leq \bar{M}$ and $\alpha \leq \bar{\alpha}$ respectively, and (16) shows the connection between the two. With interior $S>0$, condition (16) says that either both upperbound constraints are strictly binding $\left(\lambda_{1}>0\right.$ and $\left.\lambda_{2}>0\right)$ or neither are $\left(\lambda_{1}=\lambda_{2}=0\right)$. As before, there is a revenue need when $\left(\lambda_{1}>0\right)$ and $\bar{M}$ is strictly binding. As long as $\lambda_{1}>0$ (implying $\lambda_{2}>0$ as well), both $M$ and $\alpha$ increase until they hit their upperbound constraints by (14) and (15). When there is no revenue need and $\lambda_{1}=0$ (implying $\lambda_{2}=0$ as well), then either $M$ or $\alpha$ or both can be less than their upperbound constraints.

Consider first the case when both $\lambda_{1}$ and $\lambda_{2}$ are zero. In this case an increase in $\bar{M}$ or $\bar{\alpha}$ does not increase second-best $N S B$ because there is already first-best efficiency and no revenue need.

Consider next the more likely case when $\lambda_{1}>0$ and $\lambda_{2}>0$, when there is a revenue need. By (14) a $\$ 1$ increase in $\bar{M}$ increases lump-sum revenue

\footnotetext{
${ }^{11}$ Most of the studies so far have assumed separability conditions which tend to weaken complementarities and suggest that, in at least the models, when $\alpha=0$ second-best $\tau$ will be less frequently negative than other second-best proportional taxes. But with little known about actual complementarities, it is hard to say how typical is typical. In two models we were able to solve analytically, with a revenue need second-best $\tau$ was always positive when $\alpha=0$ and often but not always negative when $\alpha=\hat{t}$ (see Page and Zhang, 2000, pp. 14-20 for one of the models).
} 
by $\$ 1$. By (17) this $\$ 1$ increase in $\bar{M}$ increases $N S B$ by $\lambda_{1}$. By (15) a $\$ 1 / S$ increase in $\bar{\alpha}$ increases the rate of appropriation $\alpha$ by $\$ 1 / S$ and thus the appropriated Pigovian revenue by $(S)(\$ 1 / S)=\$ 1$. By $(17)$, the $\$ 1 / S$ increase in $\bar{\alpha}$ increases $N S B$ by $\lambda_{2} / S$. By (16) $\lambda_{2} / S=\lambda_{1}$, so the $\$ 1 / S$ increase in $\bar{\alpha}$ increases $N S B$ by the same amount as the $\$ 1$ increase in $\bar{M}$.

The two sources of incremental revenue satisfy an equivalence property for marginal changes in a second-best equilibrium, when there is a revenue need. A $\$ 1 / S$ increase in $\alpha$ can substitute for a $\$ 1$ increase in $M$ with taxes $\tau$ and $v$ held constant, and there is the same increase in revenue and the same increase in $N S B .^{12}$

We develop a variation of this idea, applied to more-than-incremental changes and to Walrasian equilibria rather than to only second-best equilibria. Omitting the qualifier "all $i$ " when it is clear by context, we will say that in two Walrasian equilibria the appropriated Pigovian revenues $\alpha_{i} S$ exchange for lump-sum taxes $M_{i}$ if the appropriated Pigovian revenues in the first equilibrium equal in amounts the lump-sum taxes in the second equilibrium, there are no lump-sum taxes in the first equilibrium and no appropriated Pigovian revenues in the second, and other taxes $\tau$ and $v$ are the same in the both equilibria. See the note ${ }^{13}$ for the definition in the other direction.

Consider two set $A$ and $B$ of the utility relevant part Walrasian equilibria (the equilibrium values of $\left(x_{1}, \ldots, x_{n}, z, L_{1}, \ldots, L_{n}, S\right)$, where $n$ is the number of individuals). In Set $A$, choose $\alpha_{i}^{\prime}$ and constrain the rates of appropriation $\alpha_{i}$ to $\alpha_{i}=\alpha_{i}^{\prime}$, and constrain lump-sum taxes $M_{i}$ to zero (constrain $M_{i}$ to $M_{i}^{\prime}=0$ ). In Set $B$, choose $M_{i}^{\prime \prime}$ and constrain the $M_{i}$ to $M_{i}=M_{i}^{\prime \prime}$, and constrain $\alpha_{i}$ to 0 .

We define an exchange as an equivalent exchange if the two equilibria in the exchange have the same utility relevant values of

$\left(x_{1}, \ldots, x_{n}, z, L_{1}, \ldots, L_{n}, S\right)$.

THEOREM 3. (Equivalence). For every interior Walrasian equilibrium with appropriated Pigovian but no lump-sum taxes, the appropriated Pigovian revenue exchanges equivalently for lump-sum taxes in another Walrasian equilibrium with lump-sum taxes but no appropriated Pigovian revenue, and vice-versa.

\footnotetext{
${ }^{12}$ In contrast, incremental changes in an unconstrained proportional labor tax $v$ and a lump-sum tax $M$ do not satisfy this property. If $v$ can be incrementally adjusted so it has the same revenue effect as a $\$ 1$ increase in $M$, the change in $v$ still leaves $N S B$ constant while the change in $M$ increases $N S B$.

${ }^{13}$ We say lump-sum taxes $M_{i}$ exchange for appropriated Pigovian revenues $\alpha_{i} S$ if the first equilibrium equal in amounts to the appropriated Pigovian revenues in the second equilibrium, there are no appropriated Pigovian revenues in the first equilibrium and no lump-sum taxes in the second, and other taxes $\tau$ and $v$ are the same in both equilibria.
} 
Proof. Starting from Set $A$, choose any admissible taxes $(\tau, v)$ and constraints $\left(\alpha_{i}=\alpha_{i}^{\prime}, M_{i}=0\right)$ and write the associated Walrasian equilibrium utility relevant values as $\left(x_{1}^{\prime}, \ldots, x_{n}^{\prime}, z^{\prime}, L_{1}^{\prime}, \ldots, L_{n}^{\prime}, S^{\prime}\right)$, or if there are multiple equilibria pick any one of them and write its utility relevant values $\left(x_{1}^{\prime}, \ldots, x_{n}^{\prime}, z^{\prime}, L_{1}^{\prime}, \ldots, L_{n}^{\prime}, S^{\prime}\right)$.

The first-order conditions (A1'), (A2') and (A3') in the Appendix for this equilibrium are same as for an equilibrium in Set B with the same taxes $(\tau, v)$ and corresponding constraints $\left(\alpha_{i}=0, M_{i}=M_{i}^{\prime \prime}=\alpha_{i}^{\prime} S^{\prime}\right)$. So we can find an equilibrium in Set $B$ with the same $\left(x_{1}^{\prime}, \ldots, x_{n}^{\prime}, z^{\prime}, L_{1}^{\prime}, \ldots, L_{n}^{\prime}, S^{\prime}\right)$, if each $i$ 's wealth is the same in the two equilibria and the government revenue from $M_{i}^{\prime \prime}$ in (6') in Set $B$ is the same amount as the government revenue from $\alpha_{i}^{\prime} S^{\prime}$ in Set $A$. These last two conditions are met by the choice of constraints in Set $B,\left(\alpha_{i}=0, M_{i}^{\prime \prime}=\alpha_{i}^{\prime} S^{\prime}\right)$.

The Pigovian revenues exchange for lump-sum taxes because $M_{i}^{\prime \prime}=\alpha_{i}^{\prime} S^{\prime}$ and the taxes $(\tau, v)$ are the same in both equilibria. The exchange is equivalent because the two equilibria have the same utility relevant values $\left(x_{1}^{\prime}, \ldots, x_{n}^{\prime}, z^{\prime}, L_{1}^{\prime}, \ldots, L_{n}^{\prime}, S^{\prime}\right)$.

Making the exchange the other way, choose any admissible taxes $(\tau, v)$ and constraints $\left(\alpha_{i}=0, M_{i}=M_{i}^{\prime \prime}\right)$ in Set $B$ and write its associated Walrasian equilibrium as $\left(x_{1}^{\prime \prime}, \ldots, x_{n}^{\prime \prime}, z^{\prime \prime}, L_{1}^{\prime \prime}, \ldots, L_{n}^{\prime \prime}, S^{\prime \prime}\right)$, or if there are multiple equilibria pick any one of the multiple equilibria and write its utility relevant values $\left(x_{1}^{\prime \prime}, \ldots, x_{n}^{\prime \prime}, z^{\prime \prime}, L_{1}^{\prime \prime}, \ldots, L_{n}^{\prime \prime}, S^{\prime \prime}\right)$. The rest of the argument follows correspondingly to that for the first exchange.

Because an equivalent exchange between appropriated Pigovian revenues and lump-sum taxes leads to Walrasian equilibria with the same values of the utility relevant variables, the distortionary and distributional effects of the appropriated Pigovian revenues are the same as the exchange equivalent lump-sum taxes. ${ }^{14}$

Case 1-3 of Figure 1 illustrate equivalent distortionary and distributional effects. Starting with Case 1, with constraints $\alpha_{i}=\alpha=0$ and without lump-sum taxes or appropriated Pigovian revenues, relax the constraints on lump-sum taxes to $\bar{M}_{i}^{\prime \prime}>0$ in Case 2 , where for later use $M_{i}^{\prime \prime}$ is chosen to equal the Pigovian compensation $(\hat{t}-\alpha) S^{\prime}=\hat{t} S^{\prime}$. Move form Case 2 to Case 3 by an equivalent exchange of lump-sum taxes for appropriated Pigovian revenues. The distortionary and distributional effects of moving

\footnotetext{
${ }^{14}$ The complication of possible multiple equilibria is of course a problem not limited to the analysis of environmental taxes. It helps, though, that in Theorem 3 the matching of first-order conditions leads to a matching of multiple equilibria when there are multiple equilibria. Further restrictions, for example, $U^{\prime}=x_{i}^{\alpha}(E / S)^{1-\alpha}+e(z)-L_{i}$ and $f\left(L_{x}, S\right)=L_{x}^{b} S(1-b)$ for $0<a, b<1$, positive constant $E$, and concave $e($.$) , provides$ uniqueness when there is a Walrasian equilibrium.
} 
FIG. 1. Second-Best Equilibria for Differing Constraints

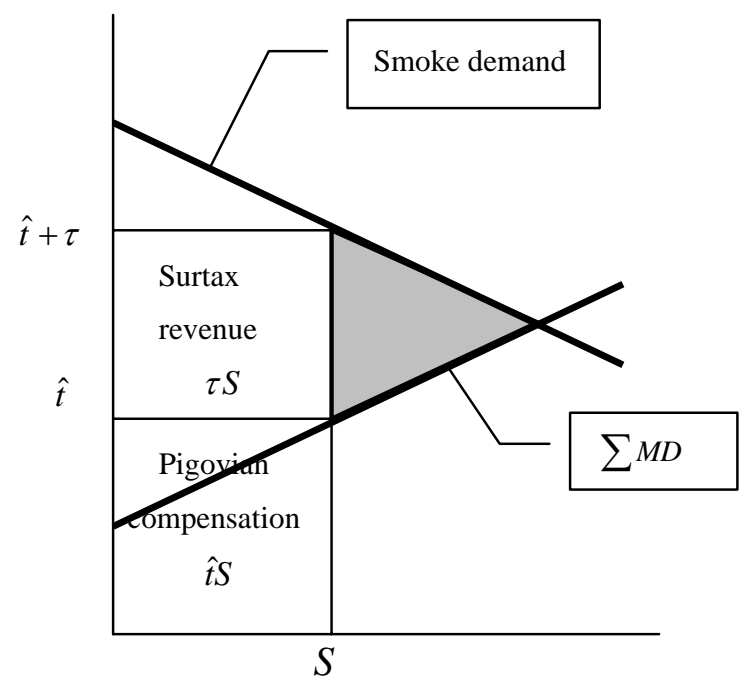

Case 1: Neither lump sum nor appropriated Pigovian revenue $\alpha_{i}=M_{i}=0 ; \tau, v$ unconstrained

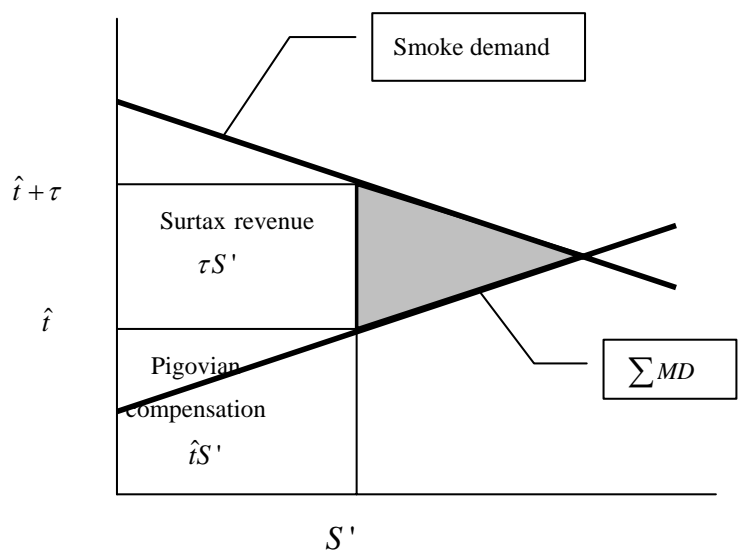

Case 2: lump sum $\alpha_{i}=0, M_{i}=M_{i}^{\prime \prime}=\alpha_{i}^{\prime} S^{\prime}>0, \tau, v$ unconstrained

from Case 1 to Case 2 are the same as in moving from Case 1 to Case 2, because Case 2 and 3 have the same values of their utility relevant variables.

The first part of Corollary 2 follows from Theorem 3.

Corollary 2. (Extension of Sandmo's Observation). In each interior Walrasian equilibrium, appropriated Pigovian revenues without lump-sum 


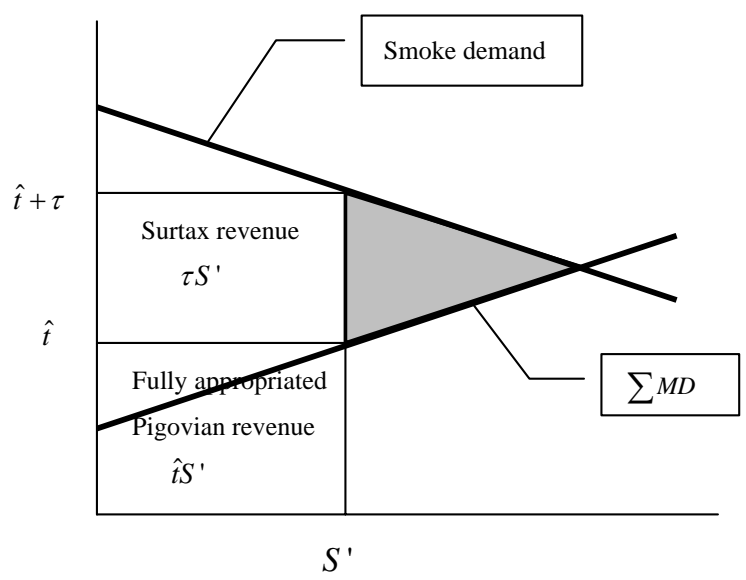

Case 3: Equivalent exchange for appropriated Pigovian revenue $\alpha_{i}=\alpha_{i}^{\prime}=\hat{t}_{i}, M_{i}=M_{i}^{\prime}=0 ; \tau, v$ constrained to the value of $\tau, v$ of Case 2

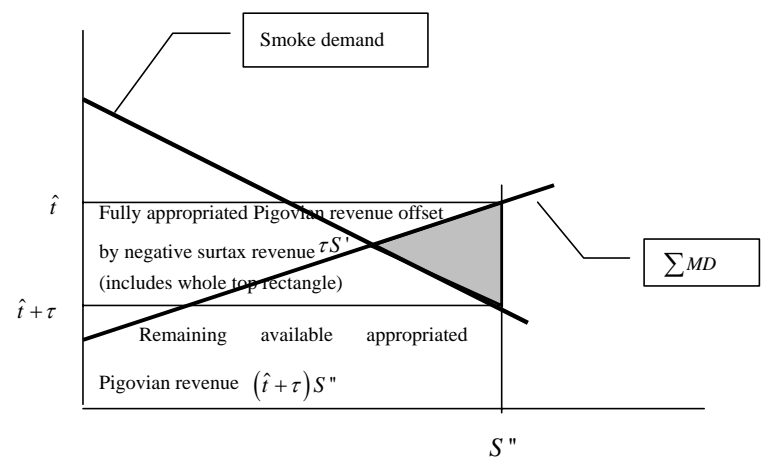

Case 4: Recent literature Same as Case 3 except $\tau, v$ unconstrained

taxes exchange equivalently for lump-sum taxes without appropriated Pigovian revenues, and in the exchange the appropriated Pigovian revenues have the same non-distortionary and distributional effects as the lump-sum taxes; and in the special case when the fully appropriated Pigovian revenues, without lump-sum taxes, equal the revenue need and are used to meet it, there is first-best efficiency with other taxes set at zero.

The special case is Sandmo's original observation, with distortionary costs in the tax system. 


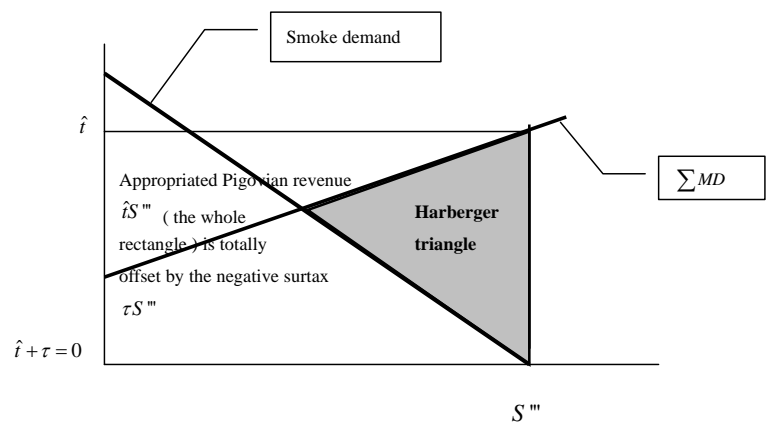

Case 5: Non-Regulation Same as Case 4 except $\tau$ constrained to $\tau=-\hat{t}$, $v$ unconstrained

Finally, to compare second-best efficiencies, write $W E^{A}\left(\tau, v \mid \alpha_{i}=\alpha_{i}^{\prime}, M_{i}=\right.$ 0 ) for the Walrasian equilibrium associated with the choice of constraints $\left(\alpha_{i}=\alpha_{i}^{\prime}, M_{i}=0\right)$ in Set $A$ and taxes $(\tau, v)$, and if there are multiple equilibria pick the one with the highest $N S B$ for this mapping. Write $W E^{B}\left(\tau, v \mid \alpha_{i}=0, M_{i}=M_{i}^{\prime \prime}\right)$ for the Walrasian equilibrium associated with the choice of constraints $\left(\alpha_{i}=0, M_{i}=M_{i}^{\prime \prime}\right)$ in Set $B$ and taxes $(\tau, v)$, and if there are multiple equilibria pick the one with highest $N S B$ for this mapping. It follows from the proof of Theorem 3 that for the same taxes $(\tau, v)$

$$
\begin{aligned}
& W E^{B}\left(\tau, v \mid \alpha_{i}=0, M_{i}=M_{i}^{\prime \prime}\right) \\
= & \left(x_{1}^{\prime \prime}, \ldots, x_{n}^{\prime \prime}, z^{\prime \prime}, L_{1}^{\prime \prime}, \ldots, L_{n}^{\prime \prime}, S^{\prime \prime}\right) \\
= & \left(x_{1}^{\prime}, \ldots, x_{n}^{\prime}, z^{\prime}, L_{1}^{\prime}, \ldots, L_{n}^{\prime}, S^{\prime}\right) \\
= & W E^{A}\left(\tau, v \mid \alpha_{i}=\frac{M_{i}^{\prime \prime}}{S^{\prime \prime}}, M_{i}=0\right) .
\end{aligned}
$$

Modify (18) to $\left(18^{\prime}\right)$ by adding the extra constraint $S^{\prime}=S^{\prime \prime}$ on the right side of the equation:

$$
W E^{B}\left(\tau, v \mid \alpha_{i}=0, M_{i}=M_{i}^{\prime \prime}\right)=W E^{A}\left(\tau, v \mid \alpha_{i}=\frac{M_{i}^{\prime \prime}}{S^{\prime \prime}}, M_{i}=0, S^{\prime}=S^{\prime \prime}\right),
$$

where this extra constraint is satisfied in Theorem 3, and consider the following steps.

First, on the left side of $\left(18^{\prime}\right)$ maximize $N S B$ over $(\tau, v)$ to find the second-best Walrasian equilibrium for the constraints $\left(\alpha_{i}=0, M_{i}=M_{i}^{\prime \prime}\right)$. For the same values of $(\tau, v)$ on the right side, the lump-sum taxes exchange 
equivalently for appropriated Pigovian revenues. With the same utility relevant variables in the two equilibria, the $N S B$ are the same in the two equilibria. Second, on the right side (18') maximize the $N S B$ over $(\tau, v)$ for the constraints $\left(\alpha_{i}=\frac{M_{i}^{\prime \prime}}{S^{\prime \prime}}, M_{i}=0, S^{\prime}=S^{\prime \prime}\right)$. This second $N S B$ cannot decrease and may increase. The extra constraint $S^{\prime}=S^{\prime \prime}$ insures that the individual $M_{i}$ 's equal in the first step equal the individual appropriated Pigovian revenues in the second step, and the aggregate lump-sum revenue of the first step equals the aggregate appropriated Pigovian revenue in the second-step. Summarizing,

Corollary 3. (Second-Best Efficiency). The second-best efficiency of the tax system with admissible lump sum taxes $M_{i}$ but no admissible appropriated Pigovian revenues is no higher than the second-best efficiency of the tax system with admissible appropriated Pigovian revenues $\alpha_{i} S$ equal in amount to $M_{i}$ but no admissible lump-sum taxes, where the amounts of $S$ are held constant by constraint.

\section{TAX INTERACTION EFFECTS}

Consider first the case of second-best tax interaction effects with revenue neutrality and fixed $M$ and $\alpha$. With revenue neutrality, $d \bar{G}=d\left(w L_{z}\right)=0$, and (12) reduces to $\frac{d(N S B)}{-U_{L}}=\tau d S+v d L_{x}=0$. Use the implicit function theorem to write second-best $S=S(\tau, v)$ and $L_{x}=L_{x}(\tau, v)$ as functions of the taxes $\tau$ and $v$. Taking differentials, (12) becomes

$$
\frac{d(N S B)}{-U_{L}}=\tau \frac{\partial S}{\partial \tau} d \tau+\tau \frac{\partial S}{\partial v} d v+v \frac{\partial L_{x}}{\partial \tau} d \tau+v \frac{\partial L_{x}}{\partial v} d v=0
$$

where $\tau \frac{\partial S}{\partial \tau} d \tau$ and $v \frac{\partial L_{x}}{\partial v} d v$, are "own-price" marginal tax interaction effects, and $\tau \frac{\partial S}{\partial v} d v$ and $v \frac{\partial L_{x}}{\partial \tau} d \tau$ are "cross-price" marginal tax interaction effects.

The finding of second-best environmental tax typically less than its Pigovian level (second-best $\tau<0$ ) in the recent literature assumes revenue neutrality and fully appropriated Pigovian revenue ( $\alpha=\hat{t}$ by constraint). In this case when second-best $\tau<0$, the own-price effect $\tau \frac{\partial S}{\partial \tau} d \tau$ of an incremental increase in $\tau$ on $S$ is a marginal benefit, because $\tau<0, \frac{\partial S}{\partial \tau}<0$, and $d \tau>0$. So all the other marginal distortionary costs in (19) must add to an increase in distortionary cost, for the total of all the effects to add to zero. In other words in this case an incremental increase in environmental taxes "exacerbates" the distortionary costs of other taxes.

Goulder (p.402, 2000) and Parry (p.S-65, 1995) explain their finding of second-best $\tau<0$ in terms of the cross-price interaction effect of the environmental tax in exacerbating the distortionary costs of other taxes. But 
as we saw in Section I, in a second-best equilibrium without externalities, a decrease in the distortionary cost of one tax exacerbates the distortionary costs of the remaining taxes, yet this cross-price effect is not enough to make these ordinary (Ramsey) taxes typically negative.

With environmental taxes, the own-price effect of $\tau$ on the appropriated Pigovian revenue appears to be a more determining factor. In a second-best equilibrium when there is a revenue need and strictly binding constraints on $\alpha$ and $M, d M$ must be non-positive. But when $\bar{\alpha}$ is positive and the constraint $\alpha \leq \bar{\alpha}$ is strictly binding, there is an additional revenue opportunity for $d(\alpha S)$. When $\tau$ is unconstrained, it is possible to decrease $\tau$ and through its own-price effect increase $S$ so $d(\alpha S)$ can be positive. (It is for this reason that the additional constraint $S^{\prime}=S^{\prime \prime}$ was added in Corollary 3.) The importance of the own-price effect of $\tau$ on the appropriated Pigovian revenue $\alpha S$ can be seen by ruling it out. Constrain $\alpha=0$, so the appropriated Pigovian revenue is zero whatever the value of $\tau$. With $\alpha=0$ we are back in the symmetry case of Corollary 1 with second-best $\tau$ typically positive.

The effect of the upperbound constraint on $\alpha$ is further revealed by relaxing $\bar{\alpha}$ altogether, allowing $\alpha>\hat{t}$. Then, by Theorem 2, we get first-best efficiency, in which case second-best $\tau=v=0$.

\section{POLICY}

There are several policy goals in setting environmental and other taxes, including:

- reducing environmental harms

- reducing distortionary costs

- limiting adverse distributional effects associated with lump-sum taxes

Reducing environmental harms is the specific mission goal of the Environmental Protection Agency in much the same way that limiting inflation was a mission goal of the Council on Wage and Price Stability or military capability is a mission goal of the Department of Defense. In this paper, the direct benefit of reducing the environmental harm by increasing $\tau$ when $\tau<0$ is interpreted as the same as reducing the own-price distortionary cost of smoke, and in this way the first two goals are related. The last two goals are also related in the well-known tradeoff between distortionary costs and distribution associated with the use of lump-sum taxes.

A basic policy question is how to balance the three goals. In principle, the policy tradeoff in the use of lump-sum taxes depends on how adverse are the distributional effects associated with their use. For example in a world of equals there are no adverse distributional effects from lump-sum taxes and little apparent reason to limit lump-sum taxes besides administrative 
difficulties. But in the practical, heterogeneous world, priority in the tradeoff is so strongly in favor of reducing lump-sum distributional effects that lump-sum sources are standardly ruled out altogether and $M_{i}$ is constrained to zero for all $i$, in applied policy as well as in second-best analysis.

But what about the lump-sum equivalent effects of $\alpha_{i} S$ ? These have the same adverse distributional effects as their equivalent $M_{i}$. If we rule out the ordinary $M_{i}$ shouldn't we rule out the equivalent $M_{i}$ by constraining $\alpha_{i} S=0$ ? But constraining $\alpha_{i} S=0$ (all $i$ ) means requiring individual marginal damage compensation, which as noted earlier can only be roughly estimated and implemented.

Nonetheless, in a heterogeneous world there can be important adverse distributional effects from environmental harms when there is no compensation (when the Pigovian revenue is fully appropriated) or when the appropriated Pigovian revenue is augmented by decreasing the environmental tax and increasing the environmental harm. Those more vulnerable to the environmental harms, for example those with asthma or compromised immune system, have higher marginal damages (higher $\hat{t}_{i}$ ), and bear disproportionately higher burdens.

There are three main ways of limiting or reducing adverse distributional effects associated with the appropriated Pigovian revenue $\alpha S$ : reduce the aggregate appropriation rate $\alpha$, reduce the environmental harm $S$, or target limited compensation on the most vulnerable. Some targeted compensation is done, for example, by compensating for black lung disease, but full implementation of marginal damage compensation remains impractical.

Given a choice between compensation for the harm and reduction of the harm itself, environmental legislation has shown a preference toward reductions of the harm, as a way of protecting the vulnerable. Compensation has received little attention in legislative mandates and regulation, while harm reduction has received much attention. As a practical matter, with little political demand for marginal damage compensation, and little compensation actually paid, the "coming to the nuisance" problem disappears, and the assumption of pervasive harm is no longer needed.

Case 1-5 of Figure 1 illustrate a range of policy tradeoffs with differing constraints and a revenue need. Case 4 (the recent literature) is the same as Example 1, and Case 5 (non-regulation) is the same as Example 3. Of the five cases, Case 5 , with $t=\hat{t}-\tau=\hat{t}-\hat{t}=0$, has typically the lowest environmental tax, the highest $S$, and the largest appropriated Pigovian revenue and lump-sum equivalent distributional effects (but the direct benefit of the non-distortionary Pigovian revenue is entirely used up in offsetting the environmental tax). Compared with Case 5, Case 4, with unconstrained second-best $\tau$ usually negative but not so negative as $-\hat{t}$, has a higher $N S B$ (by relaxing the constraint on $\tau$ ), and with the higher environmental tax it has a lower $S$ and smaller lump-sum equivalent distri- 
butional effects - a triple dividend over non-regulation (when second-best $\tau>-\hat{t})$.

Case 2, with $\alpha_{i}=\alpha=0$, has unconstrained $\tau$ usually positive (by Corollary 1), with $\tau$ the same in Case 3 by the equivalent exchange. Compared with Case 4, $\tau$ is higher in Cases 2 and 3, $S$ is lower, the lump-sum (or equivalent) effects are less, and the $N S B$ is lower (by the more binding constraints on $\tau$ and $v$ in Case 3). Case 1 is the only case without either lump-sum or lump-sum equivalent distributional effects. This case also has the likely highest $\tau$ (with lump-sum taxes meeting part of the revenue need, second-best $\tau$ and $v$ are likely lower in Case 2 than Case 1), but in Case 1 the $N S B$ is lower than in Cases 2 and 3 (by Theorem 2).

Not shown in Figure 1 is the case of traditional cost-benefit analysis, which is the same as Case 3, except that $\tau$ is constrained to $\tau=0$ (the environmental tax is set equal to the sum of the marginal damages, its Pigovian revenue is fully appropriated, and there are no lump-sum taxes). The constraint $\tau=0$ is less than the likely positive $\tau$ of Case 3, and more than the likely negative $\tau$ of Case 4, with $S, N S B$ and appropriated Pigovian revenue likely intermediate between Cases 3 and 4 . We label this intermediate cost-benefit Case 3a.

TABLE 1.

Likely Effects of Constraints on Policy Goals: Baseline with no Lumpsum Equivalent Distributional Effects

\begin{tabular}{|l|l|l|l|}
\hline & $\begin{array}{l}\text { Reduce } \\
\text { environmental } \\
\text { harm } S\end{array}$ & $\begin{array}{l}\text { Reduce } \\
\text { distortionary } \\
\text { costs (increase } N S B)\end{array}$ & $\begin{array}{l}\text { Reduce lump-sum } \\
\text { (or equivalent) } \\
\text { effects }(M \text { or } \alpha S)\end{array}$ \\
\hline Case 5: Non-regulation & Baseline case & Baseline case & Baseline case \\
\hline Case 4: Recent literature & Better than Case 5 & Better than Case 5 & Better than Case 5 \\
\hline Case 3a: Cost-Benefit & Better than Case 4 & Worse than Case 4 & Better than Case 4 \\
\hline Case 3: Equivalent exchange & Better than Case 3a & Worse than Case 3a & Better than Case 3a \\
\hline Case 2: Lump sum & Same as Case 3 & Same as Case 3 & Same as Case 3 \\
\hline $\begin{array}{l}\text { Case 1: No lump sum } \\
\text { or appropriated } \\
\text { Pigovian revenue }\end{array}$ & Better than Case 2 & Worse than Case 2 & $\begin{array}{l}\text { No lump-sum or } \\
\text { equivalent } \\
\text { distributional } \\
\text { effects }\end{array}$ \\
\hline
\end{tabular}

Note: Constraints for Case $3 \mathrm{a}$ are $\tau=0, \alpha_{i}=\hat{t}_{i}$, and $M_{i}=0$ (all $i$ ), for definitions of constraints for the other cases see Figure 1.

The six cases offer variations of the standard tradeoff between distortionary costs and distributional effects associated with lump-sum taxes. Table 1 summarizes the direction of changes in the tradeoff for the policy goals, comparing each with the next. The table abstracts from the costs and practicality of implementation, and Cases 3, 3a, and 4, which do not 
require individual marginal damage compensation, are more practical than the other regulatory cases. Moreover, the rankings are rough because we use the amount of the appropriated Pigovian revenue or the amount of lump-sum taxes as proxies of direction toward away from the third goal. ${ }^{15}$

Besides the main results identifying distortionary and distri butional effects of environmental taxes, a more general policy idea emerges from the analysis. With the large opportunity to raise non-distortionary revenue by appropriating the Pigovian revenue and with the difficulty in implementing Pigovian compensation there is considerable room to make policy tradeoffs. The well-known compromise struck in implementing the Title IV $\mathrm{SO}_{2}$ program is an example. Environmentalists who participated in the markup of the bill preferred a sharp, almost $50 \%$ reduction in $\mathrm{SO}_{2}$ emissions to compensation for existing pollution; polluters were willing to abate substantially in exchange for getting most of the appropriated Pigovian revenue in the form of grandfathered marketable allowances earmarked for them; and the government was willing to transfer almost all the appropriated Pigovian revenue to the polluters (96.5\% or more of the allowances are grandfathered) in exchange for a dramatically successful program. ${ }^{16}$

\section{APPENDIX}

\section{Proof of the Main Part of Observation 1}

Step (i). Fix the taxes $\gamma$ and $v$, recall $w=1$, fixed a candidate price $P_{x}$ and rental rate $r$, from (4) form the Lagrangian $\mathcal{L}^{i}=U^{i}\left(x_{i}, z, L_{i}, \bar{K}-K_{i}\right)-$ $\lambda_{i}\left(P_{x} x_{i}-L_{i}-r K_{i}-M_{i}\right)$, write $\frac{\partial \mathcal{L}^{i}}{\partial x_{i}}=U_{x}^{i}-\lambda_{i} P_{x}=0, \frac{\partial \mathcal{L}^{i}}{\partial K_{i}}=-U_{K}^{i}+\lambda_{i} r=0$, and $\frac{\partial \mathcal{L}^{i}}{\partial L_{i}}=U_{L}^{i}-\lambda_{i}=0$, and write first-order conditions (A.1); and from (5) write first-order conditions (A.2):

$$
\begin{gathered}
-U_{x}^{i} / U_{L}^{i}=P_{x} \text { and }-U_{K}^{i} / U_{L}^{i}=r \\
P_{x} f_{L}\left(L_{x}, K_{x}\right)-1=v \text {, and } P_{x} f_{K}\left(L_{x}, K_{x}\right)-r=\gamma
\end{gathered}
$$

\footnotetext{
${ }^{15}$ When individual lump-sum taxes are imposed at the same amount for each individual, the disproportionate burden falls on the poor; when individual rates of appropriated Pigovian revenue are set equal to the individual marginal damages, as they are with fully appropriated Pigovian revenues, the disproportionate burden falls on those with the highest marginal damages, the most vulnerable.

${ }^{16}$ Bovenberg and Goulder (2001) recommend a compromise for controlling the greenhouse gas $\mathrm{CO}_{2}$ but with about $90 \%$ of the appropriated Pigovian revenue retained as general revenue, and probably with taxes rather than allowances as the instrument.
} 
Step (ii). Adjust the candidate $P_{x}$ and $r$ to solve the market-clearing equations

$$
L_{x}+L_{z}=\sum L_{i}, K_{x}=\sum K_{i}, \text { and } x=\sum x_{i}
$$

Step (iii). For representative agent utilities

$$
N S B=\sum_{i} U^{i}\left(x_{i}, z, L_{i}, \bar{K}-K_{i}\right)=\sum_{i} U\left(x_{i}, z, L_{i}, \bar{K}-K_{i}\right) .
$$

Then

$$
d(N S B)=\sum\left(U_{x}^{i} d x_{i}+U_{z}^{i} d z+U_{L}^{i} d L_{i}+U_{K}^{i} d K_{i}\right)
$$

$$
\begin{aligned}
& \frac{d(N S B)}{-U_{L}} \\
= & \sum\left(P_{x} d x_{i}-\frac{U_{z}^{i}}{U_{L}^{i}} d z-d L_{i}-r d K_{i}\right) \quad\left(\text { by } U_{L}^{i}=U_{L}^{j}=U_{L} \text { and by }(\mathrm{A} .1)\right) \\
= & P_{x} \sum d x_{i}-d z \sum \frac{U_{z}^{i}}{U_{L}^{i}}-\sum d L_{i}-\sum r d K_{i} \\
= & P_{x} d x+\hat{p} d z-\sum d L_{i}-\sum r d K_{i} \\
= & P_{x}\left(f_{L} d L_{x}+f_{K} d K_{x}\right)+\hat{p} h_{L} d L_{z}-\left(d L_{x}+d K_{x}\right)-r d K_{x}(\text { by }(2),(3),(\text { A.3 })) \\
= & \left(P_{x} f_{L}-1\right) d L_{x}+\left(P_{x} f_{k}-R\right) d K_{x}+\left(\hat{p} h_{L}-1\right) d L_{z} \\
& \frac{d(N S B)}{-U_{L}}=\left(\hat{p} h_{L}-1\right) d L_{z}+\gamma d K_{x}+v d L_{x} \text { by (A.2) }
\end{aligned}
$$

\section{Proof of the Main Part of Observation 3}

We maximize $N S B=\sum_{i} U^{i}\left(x_{i}, z, L_{i}, \bar{K}-K_{i}\right)$ subject to the upperbound constraint on $M$, the constraints (A.1), (A.2), (A.3), the government's budget constraint (6), and the sum of the individuals' budget constraints 
from (4). Form the Lagrangian:

$$
\begin{aligned}
\mathcal{L}= & \sum U^{i}\left(x_{i}, z, L_{i}, \bar{K}-K_{i}\right)-\lambda_{1}(M-\bar{M}) \\
& -\lambda_{2}\left(P_{x} f_{L}-1-v\right)-\lambda_{3}\left(P_{x} f_{K}-r-\gamma\right) \\
& -\lambda_{4}\left(U_{x}+U_{L} P_{x}\right)-\lambda_{5}\left(U_{K}+U_{L} r\right) \\
& -\lambda_{6}\left(L_{x}+L_{z}-\sum L_{i}\right)-\lambda_{7}\left(K_{x}+K\right)-\lambda_{8}\left(f\left(L_{x}, K_{x}\right)-\sum x_{i}\right) \\
& -\lambda_{9}\left(z-h\left(L_{z}\right)\right)-\lambda_{10}\left(L_{z}-\gamma K_{x}-v L_{x}-M\right) \\
& -\lambda_{11}\left(P_{x} x-w \sum L_{i}-r \sum K_{i}+M\right)
\end{aligned}
$$

Condition (14) follows directly from the envelope theorem where the value function is $V_{\bar{M}}(\bar{M})=\frac{\partial \mathcal{L}}{\partial \bar{M}}=\lambda_{1}$. By the direction of the inequality constraint $M \leq \bar{M}$, we know $\lambda_{1} \geq 0$. So for a second-best equilibrium $\lambda_{1}$ must either be zero with the constraint $M \leq \bar{M}$ weakly binding or $\lambda_{1}>0$ with the constraint $M \leq \bar{M}$ strictly binding, as in (13).

\section{Proof of the Main Part of Theorem 1}

Fix $\tau, v$ and $\alpha$, and fix the candidate $P_{x}$ and $\hat{t}$. Form the Lagrangian for $\left(4^{\prime}\right)$

$$
\mathcal{L}^{i}=U^{i}\left(x_{i}, z, L_{i}, S\right)-\lambda_{i}\left(P_{x} x_{i}-L_{i}-\left(\hat{t}_{i}-\alpha_{i}\right) S-M_{i}\right),
$$

and write the first-order conditions (A.1') and (A.2') from (4')and (5'):

$$
\begin{gathered}
-U_{x}^{i} / U_{L}^{i}=P_{x} \\
P_{x} F_{L}\left(L_{x}, S\right)-1=v, \text { and } P_{x} f_{S}\left(L_{x}, S\right)-\hat{t}=\tau,
\end{gathered}
$$

where by the market failure there is no FOC corresponding to $-U_{K}^{i} / U_{L}^{i}=r$ in $\left(\mathrm{A} .1^{\prime}\right)$.

Adjust the candidate $P_{x}$ and $\hat{t}$ to solve the market-clearing equations

$L_{x}+L_{z}=\sum L_{i}$, and $x=\sum x_{i}$, and equalize the candidate $\hat{t}$ to $\sum \frac{-U_{S}^{i}}{U_{L}^{i}}$.

For representative agent utilities

$$
\begin{aligned}
& N S B=\sum_{i} U^{i}\left(x_{i}, z, L_{i}, S\right)=\sum_{i} U\left(x_{i}, z, L_{i}, S\right) . \\
& d(N S B)=\sum\left(U_{x}^{i} d x_{i}+U_{z}^{i} d z+U_{L}^{i} d L_{i}+\underline{U_{S}^{i} d S}\right)
\end{aligned}
$$




$$
\begin{aligned}
& \frac{d(N S B)}{-U_{L}} \\
& \left.=\sum\left(P_{x} d x_{i}-\frac{U_{z}^{i}}{U_{L}^{i}} d z-d L_{i}-\frac{U_{S}^{i}}{\underline{U_{L}}} d S\right) \text { (by } U_{L}^{i}=U_{L}^{j}=U_{L} \text { and by }\left(\mathrm{A} .1^{\prime}\right)\right) \\
& =P_{x} \sum d x_{i}-d z \sum \frac{U_{z}^{i}}{U_{L}^{i}}-\sum d L_{i}-d S \sum \frac{U_{S}^{i}}{U_{L}^{i}} \\
& =P_{x} d x+\hat{p} d z-\sum d L_{i}-\underline{\hat{t} d S} \text { (by definitions } \hat{p} \text { and } \hat{t} \text { and (A.3')) } \\
& =P_{x}\left(f_{L} d L_{x}+\underline{f_{S} d S}\right)+\hat{p} h_{L} d L_{z}-\left(d L_{x}+d K_{x}\right)-\underline{\hat{t} d S} \text { (by (2'), (3'), (A.3')) } \\
& =\left(P_{x} f_{L}-1\right) d L_{x}+\underline{\left(P_{x} f_{S}-\hat{t}\right) d S}+\left(\hat{p} h_{L}-1\right) d L_{z} \\
& \frac{d(N S B)}{-U_{L}}=\left(\hat{p} h_{L}-1\right) d L_{z}+\underline{\tau d S}+v d L_{x} \text { by }\left(\mathrm{A} .2^{\prime}\right)
\end{aligned}
$$

Set $\frac{d(N S B)}{-U_{L}}=0$ as a necessary condition for a second-best equilibrium.

For the case of additive separability, (A.1') - (A.3') are the same. The $N S B=\sum_{i}\left(U^{i}\left(x_{i}, z, S\right)-L_{i}\right)$ and $d(N S B)=\sum\left(U_{x}^{i} d x_{i}+U_{z}^{i} d z+U_{S}^{i} d S-\right.$ $\left.d L_{i}\right)$. With $U_{L}^{i}=-1$, the rest of the proof follows as above.

\section{Proof of Theorem 2}

Write $i$ 's utility as $U^{i}\left(x_{i}, z, L_{i}, S\right)$, for either its representative agent or additively separable form. We maximize $N S B=\sum U^{i}$ subject to the upperbound constraints on $M$ and $\alpha$, the constraints (A.1'), (A.2'), (A.3'), the government's budget constraint ( $\left.8^{\prime}\right)$, and the sum of the individuals' budget constraints. Form the Lagrangian, underlying differences with Observation 3:

$$
\begin{aligned}
\mathcal{L}= & \sum U^{i}\left(x_{i}, z, L_{i}, \underline{S}\right)-\lambda_{1}(M-\bar{M})-\lambda_{2}(\underline{\alpha-\bar{\alpha}})+\lambda_{3}\left(P_{x} f_{L}-1-v\right) \\
& -\lambda_{4}\left(P_{x} \underline{\left.f_{S}-\hat{t}-\tau\right)}-\lambda_{5}\left(U_{x}+U_{L} P_{x}\right)-\lambda_{6}\left(L_{x}+L_{z}-\sum L_{i}\right)\right. \\
& -\lambda_{7}\left(f\left(L_{x}, \underline{S}\right)-\sum x_{i}\right)-\lambda_{8}\left(z-h\left(L_{z}\right)\right)-\lambda_{9}\left(L_{z}-\underline{\alpha S}-\underline{\tau S}-v L_{x}-M\right) \\
& -\lambda_{10}\left(P_{x} x-w \sum L_{i}-\underline{\hat{t} S}+\underline{\alpha S}+M\right)
\end{aligned}
$$

Condition (17) follows from the envelope theorem where the value functions are $V_{\bar{M}}(\bar{M})=\frac{\partial \mathcal{L}}{\partial \bar{M}}=\lambda_{1}$ and $V_{\bar{\alpha}}(\bar{\alpha})=\frac{\partial \mathcal{L}}{\partial \bar{\alpha}}=\lambda_{2}$. By the direction of the inequality constraint $\alpha \leq \bar{\alpha}$, we know $\lambda_{2} \geq 0$. So for a secondbest equilibrium $\lambda_{2}$ must either be zero or the constraint $\alpha \leq \bar{\alpha}$ must be strictly binding, and (15) follows. Condition (14) follows as in the proof of Observation 3. 
For (16), note that in the second-best equilibrium,

$$
\begin{gathered}
\frac{\partial \mathcal{L}}{\partial \alpha}=-\lambda_{2}+\lambda_{9} S-\lambda_{10} S=-\lambda_{2}+S\left(\lambda_{9}-\lambda_{10}\right)=0 \text { and } \\
\frac{\partial \mathcal{L}}{\partial M}=-\lambda_{1}+\lambda_{9}-\lambda_{10}=-\lambda_{1}+\left(\lambda_{9}-\lambda_{10}\right)=0 ; \text { so } \\
S \lambda_{1}=\lambda_{2}
\end{gathered}
$$

\section{REFERENCES}

Bovenberg, Lans and Lawrence Goulder, 2002. Environmental taxation and regulation. In: Handbook of Public Economics, Volume 3, Part 2.

Bovenberg, Lans and Lawrence Goulder, 2001. Addressing industry-distributional concerns in the U.S. Climate Change Policy. MS. December.

Bovenberg, Lans and Rund A de Mooij, 1994. Environmental levies and distortionary taxation. American Economic Review 84 (4), 1085-9.

Coase, Ronald, 1960. The problem of social cost. The Journal of Law and Economics October, 3, 1-44.

Environmental Protection Agency, 1999. The benefits and costs of the clean air act 1990 to 2010: Report to congress, The U.S. Environmental Protection Agency, Washington, DC, November.

Espinosa, J. Andres and V. Kerry Smith, 2002. Environmental levies with nonseparable damages. Draft Paper, North Carolina State University.

Fullerton, Don and Gilbert Metcalf, 2001. Environmental controls, scarcity rents, and pre-existing distortions. Journal of Public Economics 80, 249-267.

Goulder, Lawrence, 2000. Environmental policy making in a second-best setting. In: Economics of the Environment: Selected Readings. Robert Stavins, ed. W.W.Norton \& Company, New York, 396-427.

Goulder, Lawrence, Ian Parry, Robert Williams, and Dallas Burtraw, 1999. Cost effectiveness of alternative instruments for environmental protection in a second-best setting. Journal of Public Economics 72(3), 329-360.

Green, Jerry and Jean-Jacques Laffont, 1980. Incentives in Public Decision-Making. North Holland, Amsterdam.

Kaplow, Louis, 1996. The optimal supply of public goods and the distortionary cost of taxation. National Tax Journal Vol. XLIX No.4.

Newman, Peter and Jeffery Kenworthy, 1999. Sustainability and Cities-Overcoming Automobile Dependence. Island Press, Washington, D.C.

Oates, Wallace, 1994. Green taxes: Can we protect the environment and improve the tax system at the same time? Presidential Address at the annual meeting of the Southern Economic Association, Orlando, Florida, Nov. 21.

Page, Talbot and Qinghua Zhang, 2000. The foundational difference between environmental and other taxes. Brown University Working Paper, No. 2000-4, August 10 revision. 
Parry, Ian, 1995. Pollution taxes and revenue recycling. Journal of Environmental Economics and Management 29, S-64-S-77.

Parry, Ian, 1997. Reducing carbon emission: Interactions with the Tax System Raise the Cost. Resources, Summer.

Porter, Richard, 1999. Economics at the wheel: The costs of cars and drivers. New York, Academic Press.

Sandmo, Agnar, 1975. Optimal taxation in the presence of externalities. Swedish Journal of Economics, 86-98.

Shrank, David and Tim Lomax, 2001. 2001 urban mobility report. Texas Transportation Institute. Texas A \& M University, May, 2001. 